\title{
Optimization of Ultrasound-Assisted Extraction Procedure to Determine Antioxidant Capacity of Rapeseed Cultivars
}

\author{
Aleksandra Szydłowska-Czerniak • Agnieszka Tułodziecka
}

Received: 8 April 2014 / Accepted: 28 July 2014 / Published online: 13 August 2014

(C) The Author(s) 2014. This article is published with open access at Springerlink.com

\begin{abstract}
Ultrasound-assisted extraction (UAE) was applied to extract total antioxidants from two rapeseed varieties. The antioxidant capacity of spring and winter rapeseed cultivars was determined by two different analytical methods: $2,2^{\prime}-$ azinobis-3-ethylbenzothiazoline-6-sulfonic acid (ABTS) and 2,2'-diphenyl-1-picrylhydrazyl (DPPH). Effects of three independent variables, sonication time $(t)$, volume of methanol-torapeseed weight ratio $(\mathrm{V} / \mathrm{m})$, and concentration of methanol $(c)$ on the antioxidant capacity of rapeseed varieties, were studied by response surface methodology (RSM). Box-Behnken design (BBD) was used to obtain the optimal conditions of the UAE. The optimal UAE conditions were evaluated with an extraction time of $13.8 \mathrm{~min}$, a solvent-to-material ratio of $26.2 \mathrm{~mL} / \mathrm{g}$ and a solvent concentration of $50.3 \%$ for antioxidant capacity of spring rapeseed cultivar (ABTS $=62.7 \mathrm{mmol}$ Trolox equivalent (TE) $/ 100 \mathrm{~g}$, DPPH $=38.3 \mathrm{mmol} \mathrm{TE} / 100 \mathrm{~g}$ ), whereas the predicted optimum $t=13.3 \mathrm{~min}, V / \mathrm{m}=29.5 \mathrm{~mL} / \mathrm{g}$, and $c=38.3 \%$ resulted in ABTS $=62.0 \mathrm{mmol} \mathrm{TE} / 100 \mathrm{~g}$, $\mathrm{DPPH}=48.6 \mathrm{mmol} \mathrm{TE} / 100 \mathrm{~g}$ for a winter rapeseed cultivar. Results of ABTS and DPPH determinations correlate with the predicted values $\left(R^{2}=0.9435\right.$ and 0.9796 for the spring rapeseed variety and $0.9952,0.9252$ for the winter rapeseed variety).
\end{abstract}

Keywords Ultrasound-assisted extraction $\cdot$ Rapeseed cultivars $\cdot$ Antioxidant capacity $\cdot$ Response surface methodology

\footnotetext{
A. Szydłowska-Czerniak $(\bowtie) \cdot A$. Tułodziecka

Faculty of Chemistry, Nicolaus Copernicus University, 7 Gagarin Street, 87-100 Toruń, Poland

e-mail: olasz@umk.pl
}

\section{Introduction}

Rapeseed is the most important oilseeds crop in northern Europe and Canada. All rapeseed varieties were developed from Brassica napus and Brassica rapa. Rapeseed cultivars are classified as winter or spring types according to their vernalization requirement in order to induce flowering. Winter rapeseed varieties predominantly planted in Europe and Asia can only turn from vegetative to reproductive growth after a long period of low temperatures (vernalization), whereas spring rapeseed cultivars suited to the climatic conditions in Canada, northern Europe, and Australia can reproduce without vernalization (Friedt et al. 2007, Yang et al. 2013). Therefore, in Poland, the majority of the production is winter rapeseed, while spring rapeseed is occasionally planted. Winter rapeseed varieties are usually higher yielding (41.9$44.2 \%)$ than spring rapeseed varieties (25.6-33.1\%). According to the Research Centre for Cultivar Testing (COBORU) reports (2003-2012 years), oil contents in spring (44.8-46.3 \%) and winter (45.9-46.1\%) rapeseed varieties were similar. Moreover, spring rapeseed cultivars contain lower amounts of glucosinolates $(8.1-8.2 \mu \mathrm{mol} / \mathrm{g})$ and fiber (4.7-8.3\%) when compared to winter rapeseed cultivars (8.6$10.6 \mu \mathrm{mol} / \mathrm{g}$ and $4.9-9.2 \%$, respectively). However, spring rapeseed varieties have higher level of protein (22.9-41.8 \%) than winter rapeseed varieties (19.8-38.2\%). Breeding developments led to the production of single-low (low amount of erucic acid, 22:1 n-9) and double-low or double zero " 00 " (low erucic acid content $(<2 \%)$ in the oil and low glucosinolates level $(<30 \mu \mathrm{mol} / \mathrm{g})$ in the meal) rapeseed cultivars. Moreover, rapeseed is rich in bioactive compounds including water-soluble compounds (phenolics, mainly sinapine - about $80 \%$ of the total phenolics; sinapic acid - about $70 \%$ of the free phenolic acids; as well as condensed tannins-less than $3 \%$ ) and lipid-soluble compounds such as phytosterols (sitosterol, campesterol, brassicasterol, $\Delta 5$-avenasterol, stigmasterol), tocopherols ( $\alpha$ - 
tocopherol, $\gamma$-tocopherol, and plastochromanol-8), and carotenoids (predominantly xanthophylls). Furthermore, phenolic compounds in rapeseed can be divided into three fractions: free phenolic acids, soluble esters and glycosides of phenolic acids, and insoluble-bound phenolic compounds (Shahidi and Naczk 1992). The total content of polar phenolics in rapeseed is significantly higher (about ten times) than those of insoluble components. Therefore, more polar solvent such as methanol and their aqueous mixture are usually used for extraction of phenolics from rapeseed (Amarowicz et al. 2003; Dwiecki et al. 2012; Farag et al. 2013; Khattab et al. 2010; Maltas and Yildiz 2011; Matthäus 2002; Szydłowska-Czerniak et al. 2010, 2011, 2013). Antioxidants present in rapeseed and its products are important in the prevention and treatment of coronary heart diseases, neurodegenerative and autoimmune diseases, aging, cancers, diabetes, hypertension, and rheumatoid arthritis and exhibit antiradical activity (Szydłowska-Czerniak 2013).

Only few methods, 2,2'-diphenyl-1-picrylhydrazyl (DPPH) (Amarowicz et al. 2000, 2003; Dwiecki et al. 2012; Farag et al. 2013; Khattab et al. 2010; Matthäus 2002; Szydłowska-Czerniak et al. 2010, 2011; SzydłowskaCzerniak and Tułodziecka 2013; Yoshie-Stark et al. 2006), ferric-reducing antioxidant power (FRAP) (SzydłowskaCzerniak et al. 2010, 2011; Szydłowska-Czerniak and Tułodziecka 2013), reducing power (Amarowicz et al. 2000, 2003), oxygen radical absorbance capacity (ORAC) (Szydłowska-Czerniak et al. 2010), cupric reducing antioxidant capacity (CUPRAC) (Maltas and Yildiz 2011), $\beta$-carotene-linoleic acid (Amarowicz et al. 2003; Maltas and Yildiz 2011; Matthäus 2002), scavenging ability of hydrogen peroxide (Maltas and Yildiz 2011), electron spin resonance (ESR) (Matthäus 2002), enhanced chemiluminescence (ECL) (Amarowicz et al. 2003), photochemiluminescence (PCL) (Amarowicz et al. 2003), and assay based on formation of silver nanoparticles (AgNP) (Szydłowska-Czerniak and Tułodziecka 2013), were used for determination of antioxidant capacity of different rapeseed varieties.

However, one of the most important steps during analysis of total antioxidants is the sample preparation. Different traditional methods such as boiling, heating, conventional solvent, and Soxhlet extractions have been used to extract antioxidant compounds from rapeseed samples (Amarowicz et al. 2003; Dwiecki et al. 2012; Maltas and Yildiz 2011; Szydłowska-Czerniak and Tułodziecka 2013). These procedures of sample preparation include the consumption of large amount of solvent, long extraction time, loss of phenols due to oxidation, hydrolysis, and ionization during extraction. Therefore, ultrasound-assisted extraction (UAE) of bioactive compounds is one of the upcoming extraction techniques that can offer high reproducibility in a shorter time, simplified manipulation, reduced solvent consumption and temperature, and lower energy input (Chemat et al. 2011).
Moreover, response surface methodology (RSM) was successfully applied for optimization of the UAE of antioxidants from different food products (Morelli and Prado 2012; Tabaraki et al. 2012; Wang et al. 2008).

However, the application of the RSM to optimization of the UAE of total antioxidants from rapeseed cultivars has not been reported. Only, Matthäus (2002) and Khattab et al. (2010) extracted antioxidants from defatted oilseeds meal using sonication for 45 and $1 \mathrm{~min}$, respectively, but the optimum conditions of these extraction procedures were not found.

Furthermore, there has been no reference to the determination of antioxidant capacity of rapeseed varieties by 2,2'-azinobis-3-ethylbenzothiazoline-6-sulfonic acid (ABTS) method, which is suitable to assess the antiradical capacity of both hydrophilic and lipophilic antioxidants present in oilseeds (Prior et al. 2005; Re et al. 1999).

This work is focused on the optimization of the UAE conditions for compounds with high antioxidant capacity in spring and winter rapeseed cultivars. Therefore, the RSM was used for evaluation of the effects of the three independent variables, sonication time $(t)$, solvent-to-material ratio $(\mathrm{V} / \mathrm{m})$, concentration of solvent $(c)$, and their interactions on the response variables: antioxidant capacity of rapeseed extracts determined by two modified analytical methods: ABTS and DPPH. These two spectrophotometric methods were compared, because they are quick, convenient in application, and based on the capability of antioxidants to scavenge the nitroradicals: $\mathrm{ABTS}^{\circ+}$ and $\mathrm{DPPH}^{\circ}$ by the single-electron transfer (SET) and the hydrogen-atom transfer (HAT) mechanisms. Therefore, the mixed-mode assays of ABTS and DPPH cannot correlate well with other antioxidant capacity methods that measure oxyl-radical scavenging. The use of similar methods in terms of their assay principle and somewhat differ in experimental conditions helps to determine differences in total antioxidant compounds extracted from spring and winter rapeseed cultivars.

\section{Materials and Methods}

\section{Reagents}

All reagents were of analytical or HPLC grade. 2,2'-Azinobis(3ethylbenzothiazoline-6-sulfonic acid) diammonium salt (ABTS), 2,2'-diphenyl-1-picrylhydrazyl radical (DPPH, 95 \%), 6-hydroxy-2,5,7,8-tetramethylchroman-2-carboxylic acid (Trolox (TE), $97 \%$ ), potassium persulfate, ethanol (96.0\%), and methanol (99.8\%) were purchased from SigmaAldrich (Poznań, Poland). Redistilled water was used for preparation of solutions. 


\section{Plant Materials}

Two black-seeded spring (S) and winter (W) open pollinated rapeseed varieties of $B$. napus with a reduced content of glucosinolates $(7.9 \mu \mathrm{mol} / \mathrm{g}$ for $\mathrm{S}$ and $9.2 \mu \mathrm{mol} / \mathrm{g}$ for $\mathrm{W})$ and without erucic acid (double low, 00) were provided by commercial supplier HR Strzelce, Poland. Rapeseed samples in the original packing were stored in the dark at ambient temperature, until treatment and further analysis.

\section{Ultrasound-Assisted Extraction}

Rapeseed samples were ground using a Retsch grinder and sieved to a particle size of $0.50 \mathrm{~mm}$. Methanol and its mixtures with different proportions of water are very common solvents for extraction of rapeseed phenolics. Therefore, methanolic extracts of spring and winter rapeseed cultivars were prepared by ultrasound-assisted extraction before the determination of their antioxidant capacity. A portion $(2.0 \mathrm{~g})$ of grounded rapeseed and 10, 15, and $20 \mathrm{~mL}$ of methanol with increasing concentration ( $c=25,50$, and $75 \%$, respectively) were transferred into beakers and placed exactly at the center of the ultrasonic cleaning bath (5200DTD, Chemland, Poland, $300 \times 240 \times 150 \mathrm{~mm}$ ) with a frequency of $40 \mathrm{kHz}$, ultrasound input power of $180 \mathrm{~W}$, and heating power of $800 \mathrm{~W}$, equipped with digital timer and temperature controller. The sample and solvent level in the beaker was $3.5 \mathrm{~cm}$ below the water surface in the ultrasonic bath. The height of the bottom surface of the beaker from the bottom surface of the tank (face of transducers) was $4.5 \mathrm{~cm}$. The UAE was performed for 2, 4, and $6 \mathrm{~min}$, and the temperature was kept constant at $25 \pm 0.3{ }^{\circ} \mathrm{C}$. The same rapeseed sample was extracted in triplicate. Therefore, solvent-to-rapeseed flour ratio equals to $15 \mathrm{~mL} / \mathrm{g}(10 \mathrm{~mL} \times 3 /$ $2 \mathrm{~g}), 22.5 \mathrm{~mL} / \mathrm{g}(15 \mathrm{~mL} \times 3 / 2 \mathrm{~g})$, and $30 \mathrm{~mL} / \mathrm{g},(20 \mathrm{~mL} \times 3 / 2 \mathrm{~g})$, while each rapeseed sample was ultrasound treated for $t=$ $6 \min (2 \min \times 3), 12 \min (4 \min \times 3)$, and $18 \min (6 \min \times$ 3 ), respectively. The residual rapeseed flour was separated by centrifugation (centrifuge MPW-310, Labo-Mix, Poland, 4,500 rpm, $15 \mathrm{~min}$ ). The pooled extracts were filtered and stored in a refrigerator prior to analysis.

\section{Antioxidant Capacity Determination}

\section{ABTS Method}

The spectrophotometric ABTS method was used for antioxidant capacity determination of rapeseed extracts according to Re et al. (1999) with modifications. ABTS radical cation $\left(\mathrm{ABTS}^{\bullet+}\right.$ ) was produced by reacting $7 \mathrm{mmol} / \mathrm{L}$ ABTS stock solution with $2.45 \mathrm{mmol} / \mathrm{L}$ potassium persulfate at a ratio of $1: 0.5$, and the mixture was kept in the dark at room temperature for 12-16 $\mathrm{h}$ before use. For the study of rapeseed extracts, the $\mathrm{ABTS}^{\cdot+}$ solution was diluted with ethanol to an absorbance of $0.70( \pm 0.02)$ at $734 \mathrm{~nm}$. Briefly, $0.01 \mathrm{~mL}$ of methanolic extracts was added to $2.49 \mathrm{~mL}$ of $\mathrm{ABTS}^{\cdot+}$ solution and the mixture was incubated at $30{ }^{\circ} \mathrm{C}$ for $1 \mathrm{~min}$. The absorbance was measured at $734 \mathrm{~nm}$ against a reagent blank (2.5 $\mathrm{mL}$ of $\mathrm{ABTS}^{\bullet+}$ solution) using a Hitachi U-2900 spectrophotometer (Tokyo, Japan) in a 1-cm quartz cell.

\section{DPPH Method}

The modified DPPH method was used for determination of antioxidant capacity of rapeseed varieties (SzydłowskaCzerniak et al. 2010, 2011). In brief, 0.01-0.02 mL of methanol extracts of rapeseed was added to $1.99-1.98 \mathrm{~mL}$ of methanol and $0.5 \mathrm{~mL}$ of DPPH methanolic solution $(304.0 \mu \mathrm{mol} / \mathrm{L})$. The mixture was shaken vigorously and left in darkness for $15 \mathrm{~min}$. The absorbance was measured at $517 \mathrm{~nm}$ against a reagent blank $(2 \mathrm{~mL}$ of methanol $+0.5 \mathrm{~mL}$ of DPPH methanolic solution) using a Hitachi U-2900 spectrophotometer (Tokyo, Japan) in a 1-cm quartz cell.

\section{Calibration Curves}

Calibration curves were prepared using working solutions of Trolox (TE) in methanol between $1.00 \times 10^{-2}-1.50 \times$ $10^{-1} \mu \mathrm{mol} / \mathrm{mL}$ and $2.00 \times 10^{-2}-1.00 \times 10^{-1} \mu \mathrm{mol} / \mathrm{mL}$ for ABTS and DPPH methods, respectively. Five calibration curves for each method were plotted on the same day (Szydłowska-Czerniak et al. 2010). The least-squares method was applied to calculate the line's equations: \%ABTS $=(369.1$ $\pm 12.0) \times c_{\mathrm{TE}}[\mu \mathrm{mol} / \mathrm{mL}]+(10.3 \pm 1.1)$ and $\% \mathrm{DPPH}=(668.9 \pm$ $12.2) \times c_{\mathrm{TE}}[\mu \mathrm{mol} / \mathrm{mL}]+(2.36 \pm 0.80)$, resulting in determination coefficients, 0.9974 and 0.9988 , and the relative standard deviations (RSD, $n=5$ ) of the slopes: 0.79 and $4.73 \%$, respectively. The within day precision of each method was tested by analyzing five replicate samples containing $5.00 \times$ $10^{-2}$ and $6.00 \times 10^{-2} \mu \mathrm{mol} \mathrm{TE} / \mathrm{mL}$ for ABTS and $\mathrm{DPPH}$ methods, respectively. The obtained values of $\mathrm{RSD}=3.5 \%$ for ABTS assay and RSD $=2.4 \%$ for DPPH assay indicate reasonable repeatability of the proposed methods. Moreover, the calculated detection limits $\left(1.27 \times 10^{-2}\right.$ and $4.26 \times$ $10^{-3} \mu \mathrm{mol} \mathrm{TE} / \mathrm{mL}$ for ABTS and DPPH methods, respectively) and quantification limits $\left(4.23 \times 10^{-2}\right.$ and $1.42 \times 10^{-2} \mu \mathrm{mol} \mathrm{TE} / \mathrm{mL}$ for ABTS and DPPH methods, respectively) confirm linearity concentration ranges for antioxidant capacity determination by the modified ABTS and DPPH assays. The proposed analytical methods appeared to be sensitive (molar extinction coefficients, $\varepsilon=4.8 \times 10^{3}$ and $2.4 \times 10^{3} \mathrm{~L} \mathrm{~mol}^{-1} \mathrm{~cm}^{-1}$ for ABTS and DPPH methods). 


\section{Experimental Design and Statistical Analysis}

The results of antioxidant capacity of rapeseed cultivars determined by ABTS and DPPH methods are presented as follows: mean value of five replicates \pm standard deviation (SD). The Pearson correlation test was used to establish the correlation between two analytical methods used for determination of total antioxidant potential of rapeseed extracts. Statistically significant differences were considered at the $p<0.05$ level. One-way analysis of variance (ANOVA), followed by Duncan test, was performed to analyze the significant differences between data $(p<0.05)$.

Response surface methodology based on three-level, threevariable Box-Behnken design (BBD) was applied for the study and optimizes the effects of the UAE conditions such as sonication time $(t)$, volume of solvent-to-rapeseed weight ratio $(\mathrm{V} / \mathrm{m})$, and concentration of methanol $(c)$ on antioxidant capacities of rapeseed extracts determined by ABTS and DPPH methods. A total of 15 ultrasound treatments of rapeseed samples were carried out according to the BBD experimental design, and low, middle, and high levels of the coded values were designated for the variables as $-1,0$, and 1 , respectively. The coded and actual values of the independent variables $(t, V / m$, and $c)$ as well as experimental and predicted results of ABTS and DPPH for extracts of the studied rapeseed cultivars are listed in Tables 1 and 2.

All the responses observed were simultaneously fitted to the first-order, second-order, and partial cubic models. The determination coefficient $\left(R^{2}\right)$, the lack of fit of the studied models, and $p$ values of the parameter estimations were used to validate the models. Based on the statistical analysis (lack of fit is not significant and $R^{2}$ is the highest), the best-fitted model was the partial cubic model (PCM):

$$
\begin{aligned}
Y_{n}=\beta_{0} & +\beta_{1} \times t+\beta_{2} \times V / m+\beta_{3} \times c+\beta_{11} \times t^{2} \\
& +\beta_{22} \times(V / m)^{2}+\beta_{33} \times c^{2}+\beta_{12} \times t \times V / m \\
& +\beta_{13} \times t \times c+\beta_{23} \times V / m \times c+\beta_{112} \times t^{2} \times V / m \\
& +\beta_{113} \times t^{2} \times c
\end{aligned}
$$

where $Y_{n}$ is one of the four predicted responses; $t, V / m$, and $c$ represent the independent variables; $\beta_{0}$ is the constant; $\beta_{1}$,

\begin{tabular}{|c|c|c|c|c|c|c|c|c|c|c|}
\hline \multirow[t]{4}{*}{ Experiment } & \multicolumn{3}{|c|}{ Coded level } & \multicolumn{3}{|c|}{ Independent variables } & \multicolumn{4}{|c|}{ Dependent variables } \\
\hline & \multirow[t]{3}{*}{$X_{1}$} & \multirow[t]{3}{*}{$X_{2}$} & \multirow[t]{3}{*}{$X_{3}$} & \multirow[t]{3}{*}{$t(\min )$} & \multirow[t]{3}{*}{$V / m(\mathrm{~mL} / \mathrm{g})$} & \multirow[t]{3}{*}{$c(\%)$} & \multicolumn{2}{|c|}{ Spring rapeseed cultivar } & \multicolumn{2}{|c|}{ Winter rapeseed cultivar } \\
\hline & & & & & & & \multicolumn{2}{|c|}{$\mathrm{ABTS}^{\mathrm{a}} \pm \mathrm{SD}(\mathrm{mmol} \mathrm{TE} / 100 \mathrm{~g})$} & \multicolumn{2}{|c|}{$\mathrm{ABTS}^{\mathrm{a}} \pm \mathrm{SD}(\mathrm{mmol} \mathrm{TE} / 100 \mathrm{~g})$} \\
\hline & & & & & & & Experimental & Predicted & Experimental & Predicted \\
\hline 1 & -1 & -1 & 0 & 6 & 15 & 50 & $42.8 \pm 0.5 \mathrm{f}$ & 47.6 & $30.4 \pm 1.5 \mathrm{c}$ & 30.7 \\
\hline 2 & 1 & -1 & 0 & 18 & 15 & 50 & $51.3 \pm 1.2 \mathrm{~g}$ & 46.6 & $49.0 \pm 1.6 \mathrm{~g}$ & 48.8 \\
\hline 3 & -1 & 1 & 0 & 6 & 30 & 50 & $28.6 \pm 1.4 \mathrm{c}$ & 33.4 & $25.5 \pm 1.1 \mathrm{~b}$ & 25.8 \\
\hline 4 & 1 & 1 & 0 & 18 & 30 & 50 & $63.1 \pm 3.1 \mathrm{i}$ & 58.3 & $34.5 \pm 1.5 \mathrm{~d}$ & 34.2 \\
\hline 5 & -1 & 0 & -1 & 6 & 22.5 & 25 & $18.8 \pm 0.8 \mathrm{~b}$ & 14.1 & $23.3 \pm 1.0 \mathrm{a}$ & 23.1 \\
\hline 6 & 1 & 0 & -1 & 18 & 22.5 & 25 & $16.7 \pm 0.7 \mathrm{a}$ & 21.5 & $44.9 \pm 1.0 \mathrm{f}$ & 45.1 \\
\hline 7 & -1 & 0 & 1 & 6 & 22.5 & 75 & $32.0 \pm 1.5 \mathrm{~d}$ & 27.2 & $36.1 \pm 1.3 \mathrm{~d}$ & 35.8 \\
\hline 8 & 1 & 0 & 1 & 18 & 22.5 & 75 & $38.8 \pm 1.9 \mathrm{e}$ & 43.6 & $40.1 \pm 1.1 \mathrm{e}$ & 40.3 \\
\hline 9 & 0 & -1 & -1 & 12 & 15 & 25 & $43.6 \pm 1.4 \mathrm{f}$ & 43.6 & $24.9 \pm 1.1 \mathrm{a}, \mathrm{b}$ & 24.9 \\
\hline 10 & 0 & 1 & -1 & 12 & 30 & 25 & $33.7 \pm 0.9 \mathrm{~d}$ & 33.7 & $56.1 \pm 2.6 \mathrm{~h}$ & 56.1 \\
\hline 11 & 0 & -1 & 1 & 12 & 15 & 75 & $31.7 \pm 1.1 \mathrm{~d}$ & 31.7 & $41.0 \pm 1.4 \mathrm{e}$ & 41.0 \\
\hline 12 & 0 & 1 & 1 & 12 & 30 & 75 & $44.3 \pm 1.6 \mathrm{f}$ & 44.3 & $44.9 \pm 1.8 \mathrm{f}$ & 44.9 \\
\hline 13 & 0 & 0 & 0 & 12 & 22.5 & 50 & $61.2 \pm 2.1 \mathrm{~h}, \mathrm{i}$ & 61.1 & $64.8 \pm 1.0 \mathrm{j}$ & 64.0 \\
\hline 14 & 0 & 0 & 0 & 12 & 22.5 & 50 & $60.1 \pm 1.7 \mathrm{~h}$ & 61.1 & $61.1 \pm 2.9 \mathrm{i}$ & 64.0 \\
\hline 15 & 0 & 0 & 0 & 12 & 22.5 & 50 & $62.1 \pm 2.4 \mathrm{~h}, \mathrm{i}$ & 61.1 & $66.1 \pm 1.4 \mathrm{j}$ & 64.0 \\
\hline
\end{tabular}
$\beta_{2}$, and $\beta_{3}$ are the linear-term coefficients; $\beta_{11}, \beta_{22}$, and $\beta_{33}$ are

Table 1 Three-level Box-Behnken design with three independent variables, experimental and predicted results for the ABTS values of spring and winter rapeseed cultivar responses

Probability, $p=0.05$; different letters within the same column indicate significant differences between ABTS results of the rapeseed extracts (one-way ANOVA and Duncan test, $p<0.05$ )

$S D$ standard deviation

${ }^{\mathrm{a}} n=5$ 
Table 2 Three-level Box-Behnken design with three independent variables, experimental and predicted results for the DPPH values of spring and winter rapeseed cultivar responses

\begin{tabular}{|c|c|c|c|c|c|c|c|c|c|c|}
\hline \multirow[t]{4}{*}{ Experiment } & \multicolumn{3}{|c|}{ Coded level } & \multicolumn{3}{|c|}{ Independent variables } & \multicolumn{4}{|c|}{ Dependent variables } \\
\hline & \multirow[t]{3}{*}{$X_{1}$} & \multirow[t]{3}{*}{$X_{2}$} & \multirow[t]{3}{*}{$X_{3}$} & \multirow[t]{3}{*}{$t(\min )$} & \multirow[t]{3}{*}{$V / m(\mathrm{~mL} / \mathrm{g})$} & \multirow[t]{3}{*}{$c(\%)$} & \multicolumn{2}{|c|}{ Spring rapeseed cultivar } & \multicolumn{2}{|c|}{ Winter rapeseed cultivar } \\
\hline & & & & & & & \multicolumn{2}{|c|}{$\mathrm{DPPH}^{\mathrm{a}} \pm \mathrm{SD}(\mathrm{mmol} \mathrm{TE} / 100 \mathrm{~g})$} & \multicolumn{2}{|c|}{$\mathrm{DPPH}^{\mathrm{a}} \pm \mathrm{SD}(\mathrm{mmol} \mathrm{TE} / 100 \mathrm{~g})$} \\
\hline & & & & & & & Experimental & Predicted & Experimental & Predicted \\
\hline 1 & -1 & -1 & 0 & 6 & 15 & 50 & $20.7 \pm 0.4 \mathrm{c}$ & 21.9 & $21.4 \pm 0.3 \mathrm{~d}$ & 26.0 \\
\hline 2 & 1 & -1 & 0 & 18 & 15 & 50 & $26.6 \pm 0.7 \mathrm{f}$ & 25.4 & $29.0 \pm 1.5 \mathrm{~g}$ & 24.4 \\
\hline 3 & -1 & 1 & 0 & 6 & 30 & 50 & $23.0 \pm 0.9 \mathrm{~d}$ & 24.2 & $20.5 \pm 1.0 \mathrm{~d}$ & 25.1 \\
\hline 4 & 1 & 1 & 0 & 18 & 30 & 50 & $34.2 \pm 0.1 \mathrm{~h}, \mathrm{i}$ & 33.1 & $51.6 \pm 0.91$ & 47.0 \\
\hline 5 & -1 & 0 & -1 & 6 & 22.5 & 25 & $24.5 \pm 0.6 \mathrm{e}$ & 23.4 & $22.5 \pm 0.7 \mathrm{e}$ & 17.9 \\
\hline 6 & 1 & 0 & -1 & 18 & 22.5 & 25 & $33.3 \pm 0.8 \mathrm{~h}$ & 34.4 & $25.2 \pm 1.1 \mathrm{f}$ & 29.9 \\
\hline 7 & -1 & 0 & 1 & 6 & 22.5 & 75 & $14.2 \pm 0.5 \mathrm{~b}$ & 13.1 & $11.2 \pm 0.4 \mathrm{~b}$ & 6.6 \\
\hline 8 & 1 & 0 & 1 & 18 & 22.5 & 75 & $13.3 \pm 0.6 \mathrm{~b}$ & 14.5 & $10.3 \pm 0.4 \mathrm{~b}$ & 14.9 \\
\hline 9 & 0 & -1 & -1 & 12 & 15 & 25 & $26.2 \pm 1.0 \mathrm{f}$ & 26.2 & $14.3 \pm 0.5 \mathrm{c}$ & 14.3 \\
\hline 10 & 0 & 1 & -1 & 12 & 30 & 25 & $24.9 \pm 1.0 \mathrm{e}$ & 24.9 & $45.6 \pm 0.6 \mathrm{k}$ & 45.6 \\
\hline 11 & 0 & -1 & 1 & 12 & 15 & 75 & $11.9 \pm 0.5 \mathrm{a}$ & 11.9 & $6.9 \pm 0.3 \mathrm{a}$ & 6.9 \\
\hline 12 & 0 & 1 & 1 & 12 & 30 & 75 & $28.1 \pm 1.2 \mathrm{~g}$ & 28.1 & $11.0 \pm 0.3 \mathrm{~b}$ & 11.0 \\
\hline 13 & 0 & 0 & 0 & 12 & 22.5 & 50 & $37.3 \pm 1.0 \mathrm{j}$ & 37.1 & $31.1 \pm 1.3 \mathrm{~h}$ & 33.9 \\
\hline 14 & 0 & 0 & 0 & 12 & 22.5 & 50 & $34.7 \pm 0.3 \mathrm{i}$ & 37.1 & $36.7 \pm 0.9 \mathrm{j}$ & 33.9 \\
\hline 15 & 0 & 0 & 0 & 12 & 22.5 & 50 & $39.3 \pm 0.6 \mathrm{k}$ & 37.1 & $33.8 \pm 0.7 \mathrm{i}$ & 33.9 \\
\hline
\end{tabular}

Probability, $p=0.05$; different letters within the same column indicate significant differences between DPPH results of the rapeseed extracts (one-way ANOVA and Duncan test, $p<0.05$ )

$S D$ standard deviation

${ }^{\mathrm{a}} n=5$

Table 3 ANOVA results for the responses: ABTS and DPPH of rapeseed cultivars

\begin{tabular}{|c|c|c|c|c|c|c|c|}
\hline \multirow[t]{2}{*}{ Model parameters } & \multirow[t]{2}{*}{ df } & \multicolumn{3}{|c|}{ Spring rapeseed cultivar } & \multicolumn{3}{|c|}{ Winter rapeseed cultivar } \\
\hline & & SS & MS & $F$ value & SS & MS & $F$ value \\
\hline \multicolumn{8}{|l|}{ ABTS } \\
\hline Regression & 11 & 3,344 & 304 & $292 *$ & 3,068 & 279 & $42.0^{*}$ \\
\hline Residual & 3 & 185 & 61.8 & & 13.8 & 4.6 & \\
\hline Lack-of-fit & 1 & 183 & 183 & $176^{*}$ & 0.5 & 0.5 & 0.08 \\
\hline Pure error & 2 & 2.1 & 1.0 & & 13.3 & 6.7 & \\
\hline Total & 14 & 3,530 & & & 3,082 & & \\
\hline$R^{2}$, adjusted $R^{2}$ & $0.9435,0.7365$ & & & & $0.9952,0.9775$ & & \\
\hline \multicolumn{8}{|l|}{ DPPH } \\
\hline Regression & 11 & 1,116 & 101.4 & $18.8^{*}$ & 2,080 & 189 & $24.5^{*}$ \\
\hline Residual & 3 & 21.3 & 7.1 & & 185 & 61.7 & \\
\hline Lack-of-fit & 1 & 10.5 & 10.5 & 2.0 & 170 & 170 & $22.1 *$ \\
\hline Pure error & 2 & 10.8 & 5.4 & & 15.4 & 7.7 & \\
\hline Total & 14 & 1,137 & & & 2,265 & & \\
\hline$R^{2}$, adjusted $R^{2}$ & $0.9796,0.9049$ & & & & $0.9252,0.6507$ & & \\
\hline
\end{tabular}

$d f$ degree of freedom, $S S$ sum of squares, $M S$ mean square

*Significant at the $p<0.05$ level 
the quadratic-term coefficients; and $\beta_{12}, \beta_{13}, \beta_{23}, \beta_{112}$, and $\beta_{113}$ are the cross-term coefficients.

The significance of the independent variables, their interactions, and the goodness of fit of the PCM were determined by an analysis of variance (ANOVA) for each response. The adequacy and fitness of PCM were evaluated by coefficient of determination $\left(R^{2}\right)$, adjusted coefficient of determination (adjusted $R^{2}$ ), and $F$ value. Moreover, three-dimensional surface plots and contour plots were drawn on the basis of the PCM equations to illustrate the interactive effects of two independent variables on the responses when a third factor was kept at a constant level. Also, the fitted mathematical models were applied to determine the optimum conditions of each factor $(t, V / m$, and $c)$ for maximum antioxidant capacity of rapeseed extracts.

Besides, a hierarchical cluster analysis (HCA) using Ward method with Euclidean distances was applied to classification of rapeseed extracts into different groups (clusters) based on similarity of their antioxidant capacity determined by ABTS and DPPH methods. The HCA results were presented in a form of two-dimensional plot (dendrogram), which illustrated the clusters and correlations among rapeseed samples. The chemometric analyses were performed using the Statistica (Windows software package, version 8.0).

\section{Results and Discussion}

\section{Antioxidant Capacity of Rapeseed Varieties}

The experimental and predicted values of ABTS and DPPH of spring and winter rapeseed cultivars are listed in Tables 1 and 2. It can be noted that antioxidant capacities of the studied rapeseed extracts determined by the proposed analytical procedures differ significantly from each other ( $p$ values ranged between $0.000010-0.045$ and $0.000010-0.041$ for spring and winter cultivars, respectively, Duncan test). This variability can be explained by the influence of extraction conditions (sonication time, solvent-to-material ratio, and concentration of methanol) and analytical parameters of the applied methods, which would affect the level of antioxidants. Although, similar values of ABTS revealed extracts of spring rapeseed variety obtained under following conditions: $t=6$ and $12 \mathrm{~min} ; \mathrm{V} / \mathrm{m}=15$ and $30 \mathrm{~mL} / \mathrm{g}$; and $c=50,25$, and $75 \%$ (exps. 1, 9, and 12) as well as $t=6$ and $12 \mathrm{~min} ; \mathrm{V} / \mathrm{m}=22.5,30$, and $15 \mathrm{~mL} / \mathrm{g}$; and $c=75$ and $25 \%$ (exps. 7, 10, and 11) (Table 1). Also, DPPH results of spring rapeseed samples, which were prepared under the same ratio of $V / m=15 \mathrm{~mL} / \mathrm{g}$ (exps. 2 and 9); methanol concentration, $c=25 \%$ (exps. 5 and 10); sonication time, $t=18 \mathrm{~min}$ (exps. 4 and 6); ratio of $V / m=$ $22.5 \mathrm{~mL} / \mathrm{g}$; and solvent concentration, $c=75 \%$ (exps. 7 and 8 ), did not differ significantly (Table 2). It is noteworthy that there were no significant differences (Duncan test, $p>0.05$ ) in antioxidant capacity determined by ABTS method for samples
Fig. 1 Response surfaces and contour plots for ABTS of spring and winter rapeseed varieties expressed as a function of $t$ and $\mathrm{V} / \mathrm{m}$ (a, d) (at $\mathrm{c}=50 \%), t$ and $c(\mathbf{b}$, e) $($ at $V / m=22.5 \mathrm{~mL} / \mathrm{g}$ ), and $V / m$ and $c(\mathbf{c}, \mathbf{f})$ (at $t=12 \mathrm{~min})$

of winter cultivar extracted under different conditions (exps. 4 and 7; 5 and 9; 6 and 12;8 and 11). However, $50 \%$ methanolic extracts of winter rapeseed variety treated for $6 \mathrm{~min}$ (exps. 1 and 3) and $75 \%$ methanolic extracts (exps. 7, 8, and 12) had similar DPPH values (Table 2). Only, insignificant differences for mean ABTS values were observed between rapeseed extracts obtained under the same extraction conditions $(t=12 \mathrm{~min}, \mathrm{~V} / \mathrm{m}=$ $22.5 \mathrm{~mL} / \mathrm{g}$, and $c=50 \%$, Table 1 ).

It can be noted that ABTS (16.7-66.1 mmol TE/100 g) values were about 1.5 and 2.5 times higher in comparison with DPPH (6.9-51.6 mmol TE/100 g) results for the studied rapeseed extracts (Tables 1 and 2). Although, these two analytical methods are based on the measurement of the reducing ability of rapeseed antioxidants toward colored radical cation $\mathrm{ABTS}^{\circ+}$ and radical DPPH', respectively. This fact can be explained by the fact that the $\mathrm{ABTS}^{-+}$free radical is more sensitive to phenolic-containing compounds than DPPH* Also, carotenoids (mainly xanthophylls) and tocopherols are more efficient quenchers of $\mathrm{ABTS}^{\cdot+}$ than $\mathrm{DPPH}^{*}$. Moreover, many antioxidants present in the rapeseed extracts probably react slowly with DPPH radicals or not at all due to steric inaccessibility (Prior et al. 2005). Therefore, the proposed ABTS method is suitable to assess the antiradical capacity of both hydrophilic and lipophilic antioxidants in the same sample and should be applied for determination of antioxidant potential of oilseeds.

The highest ABTS (63.1 mmol TE/100 g) and DPPH $(51.6 \mathrm{mmol} \mathrm{TE} / 100 \mathrm{~g})$ values revealed $50 \%$ methanolic $(t=$ $18 \mathrm{~min}, V / m=30 \mathrm{~mL} / \mathrm{g}$ ) extracts of the spring and winter varieties, whereas ABTS (16.7 mmol TE/100 g) and DPPH $(6.9 \mathrm{mmol} \mathrm{TE} / 100 \mathrm{~g})$ values were the lowest for the 25 and $75 \%$ methanolic $(t=18$ and $12 \mathrm{~min}, V / m=22.5$ and $15 \mathrm{~mL} / \mathrm{g})$ extracts of spring and winter rapeseed cultivars, respectively (Tables 1 and 2). This suggests that antioxidant capacity of the resulting extracts did not increase with a line in ultrasoundassisted extraction time and solvent concentration. Ultrasound treatment of sample can induce acoustic cavitation and rupture of plant cells. For this reason, the release of components within the plant cells into the solvent and the mass transfers between the solid matrix and solvent are promoted. Usually, extraction yield of bioactive compounds increases with an increase in the extraction time, because all the plant cells will be completely cracked by the effect of acoustic cavitation. However, some components within the plant cells such as insoluble compounds and lipids suspend in the extraction liquid; therefore, permeability of the solvent is lower. Furthermore, components present in extracts can re-adsorb on the smashed plant particles due to their relatively large 
Spring rapeseed cultivar
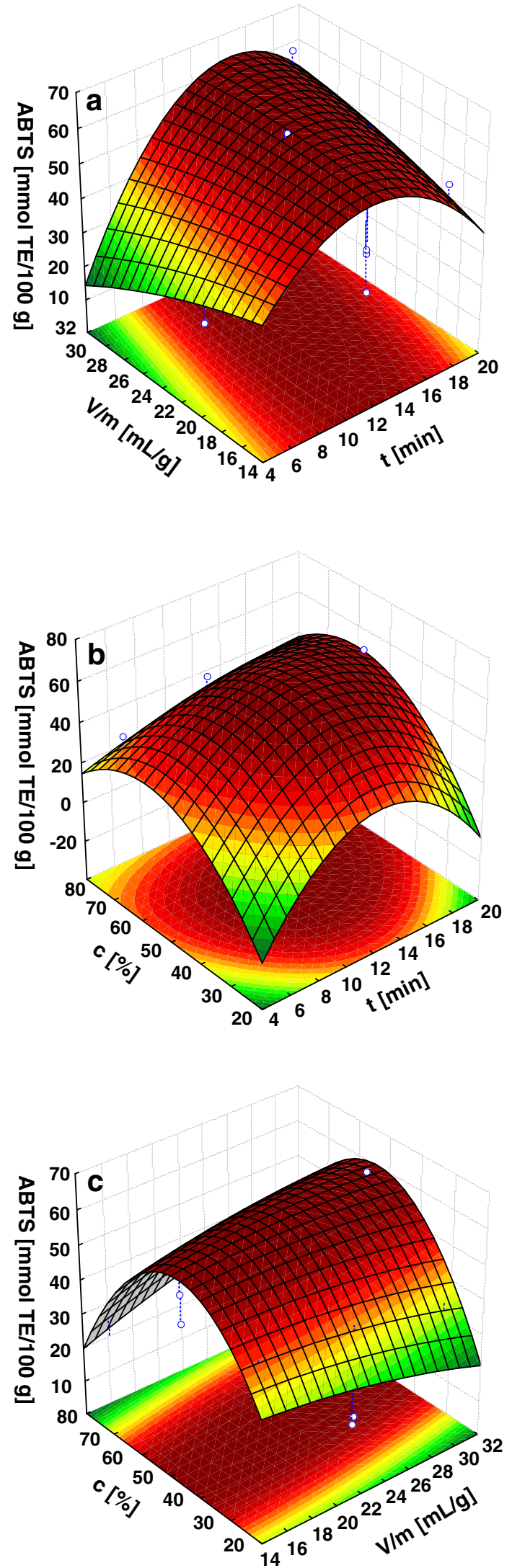

Winter rapeseed cultivar
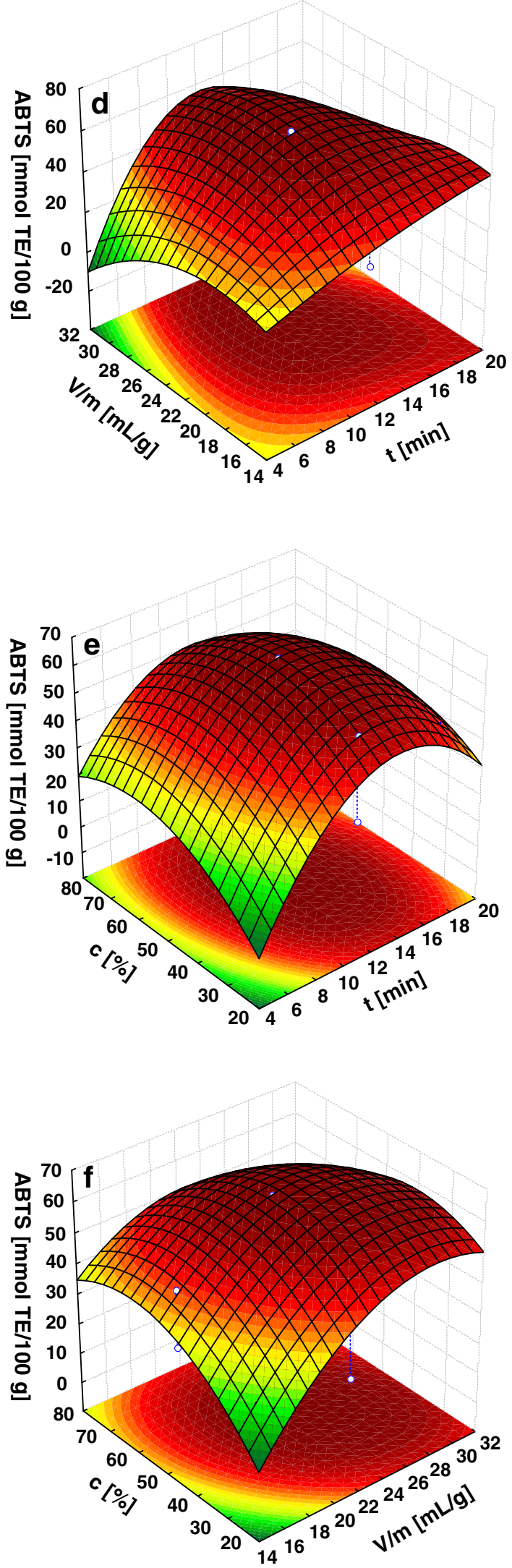
specific surface areas and decrease yields of the extracted compounds (Wang et al. 2012). For comparison, AhmadQasem et al. (2013) observed that the increase in antioxidant capacity of the olive leaf extracts was almost negligible after 15 min of extraction, which indicates that continuous ultrasound application seems to have no effect on bioactive compounds. As can be seen, $50 \%$ methanol was a better extraction solvent than 25 and $75 \%$ methanol for preparation of rapeseed samples to determine their antioxidant capacity (Tables 1 and 2). Also, higher concentrations of ethanol (70 \%) led to lower DPPH values of red grape jam extracts (1.83-2.57 mg E.Q/g jam) (Morelli and Prado 2012). On the other hand, the antioxidant capacity of the studied rapeseed cultivars increased when the solvent-to-solid ratio was increased from 15 to $30 \mathrm{~mL} / \mathrm{g}$. This fact can be explained by the fact that usage of larger volume of solvent could obtain higher amount of antioxidants, as it could accelerate diffusion of bioactive compounds, which could be favorable for increase total antioxidant capacity. Similar effect of solvent-to-solid ratio on the extraction of total antioxidants from pomegranate (Punica granatum L.) peel and bay leaves (Laurus nobilis L.) was observed by Tabaraki et al. (2012) and Muñiz-Márquez et al. (2013), respectively.

DPPH results (6.9-51.6 mmol TE/100 g) of rapeseed extracts after sonication were a significantly higher in comparison to DPPH values (3.3-7.6 mmol TE/100 g) for rapeseed extracts previously obtained by conventional solid/liquid extraction (Szydłowska-Czerniak et al. 2010, 2011). It can be noted that the DPPH results expressed as antioxidants concentrations in extracts of the studied rapeseed varieties required to reduce the DPPH radicals by $50 \%\left(\mathrm{ED}_{50}=0.14\right.$ $1.00 \mathrm{mg} / \mathrm{mL}$ ) were lower when compared to $\mathrm{ED}_{50}$ values for Lion $(3.70-4.08 \mathrm{mg} / \mathrm{mL}$ ) and Express (about $10 \mathrm{mg} / \mathrm{mL}$ ) varieties obtained by Yoshie-Stark et al. (2006), whereas similar to those reported by Matthäus (2002) $(0.2 \mathrm{mg} / \mathrm{mL}$ for extract of rapeseed variety after ultrasonic treatment) and Dwiecki et al. (2012) $(0.050-0.61 \mathrm{mg} / \mathrm{mL}$ for total phenolic and phenolic acid extracts of Aviso and PR45DO3 varieties).

The values of RSD $(n=5)$ ranged between $1.2-4.9 \%$ and $0.3-5.2 \%$, respectively, indicating reasonable repeatability of the proposed ABTS and DPPH assays for determination of antioxidant capacity of rapeseed varieties. Similar RSD values of DPPH (0.2-3.4\%) for different rapeseed cultivars were found in our previous reports (Szydłowska-Czerniak et al. 2010, 2011; Szydłowska-Czerniak and Tułodziecka 2013).

Moreover, regression analysis was performed for the correlation among antioxidant capacities of 30 rapeseed extracts (15 spring rapeseed extracts and 15 winter rapeseed extracts) determined by the proposed ABTS and the modified DPPH methods. The obtained results of antioxidant capacity indicated that there is significant, positive correlation between the ABTS and DPPH values for all the studied rapeseed extracts $(r=0.4606, p=0.010)$. This fact can be explained by the fact that the $\mathrm{ABTS}^{\circ+}$ radical enables the simultaneous determination of hydrophilic and
Fig. 2 Response surfaces and contour plots for DPPH of spring and winter rapeseed varieties expressed as a function of $t$ and $V / m(\mathbf{a}, \mathbf{d})($ at $c=$ $50 \%), t$ and $c(\mathbf{b}, \mathbf{e})($ at $V / m=22.5 \mathrm{~mL} / \mathrm{g}), V / m$ and $c(\mathbf{c}, \mathbf{f})($ at $t=12 \mathrm{~min})$

lipophilic antioxidants, whereas $\mathrm{DPPH}^{\circ}$ radical brings an important limitation to the determination of hydrophilic antioxidants. Flavonoids and other complex phenols generally exhibit moderate-to-slow reaction with $\mathrm{DPPH}^{*}$ radical.

Fitting the Models

The first-order models were used to approximate the data responses: ABTS and DPPH results of spring and winter cultivars. However, the lack-of-fit $p$ values $(0.00246-0.0474)$ were significant (except $p=0.0557$ for DPPH of the spring rapeseed samples), whereas $R^{2}(0.2266-0.6128)$ were small. Therefore, the first-order models were not adequate approximations for the studied responses, and the second-order models for data fitting were applied. Various second-order models, from interaction to partial cubic, were tested. The $R^{2}$ of the second-order models were higher $(0.9252-0.9952)$ than the first-order $(0.2266$ 0.6128 ) models, but the evaluated lack of fits were significant for ABTS of spring rapeseed cultivar $(p=0.00563)$ as well as for DPPH $(p=0.0424)$ of winter rapeseed cultivar.

The RSM was applied, and the partial cubic response surface models were fitted to each response variable: ABTS and DPPH for spring and winter varieties, respectively (Tables 1 and 2). The following regression equations were obtained:

$$
\begin{aligned}
A B T S_{S}= & -79.5+15.4 t-2.7 \mathrm{~V} / \mathrm{m}+4.0 c-0.77 t^{2}-0.026(\mathrm{~V} / \mathrm{m})^{2} \\
& -0.034 c^{2}+0.26 t \times V / m-0.23 t \times c+0.030 \mathrm{~V} / \mathrm{m} \times c \\
& -0.0047 t^{2} \times V / m+0.010 t^{2} \times c A B T S_{W}=-111.0-10.9 t \\
& +5.8 \mathrm{~V} / \mathrm{m}+3.0 c+0.61 t^{2}-0.21(\mathrm{~V} / \mathrm{m})^{2}-0.017 c^{2} \\
& +1.2 t \times V / m-0.051 t \times c-0.036 \mathrm{~V} / \mathrm{m} \times c-0.051 t^{2} \\
& \times V / m+0.0010 t^{2} \times c D P P H_{S}=-2.8-4.1 t+2.1 \mathrm{~V} / \mathrm{m} \\
& +0.32 c+0.20 t^{2}-0.085(\mathrm{~V} / \mathrm{m})^{2}-0.015 c^{2}+0.14 t \times V / m \\
& +0.11 t \times c+0.023 \mathrm{~V} / \mathrm{m} \times c-0.0047 t^{2} \times V / m-0.0053 t^{2} \\
& \times c D P P H_{W}=-53.0-1.6 t+0.049 \mathrm{~V} / \mathrm{m}+3.3 c-0.0091 t^{2} \\
& -0.0098(\mathrm{~V} / \mathrm{m})^{2}-0.022 c^{2}+0.43 t \times V / m-0.11 t \\
& \times c-0.036 \mathrm{~V} / \mathrm{m} \times c-0.013 t^{2} \times V / m+0.0044 t^{2} \times c
\end{aligned}
$$

The ANOVA results for the predicted response partial cubic models are listed in Table 3.

The ANOVA test revealed that the PCMs adequately represent responses of ABTS and DPPH values for spring $\left(R^{2}=\right.$ 0.9435 and 0.9796$)$ and winter $\left(R^{2}=0.9952\right.$, and 0.9252$)$ 
Spring rapeseed cultivar
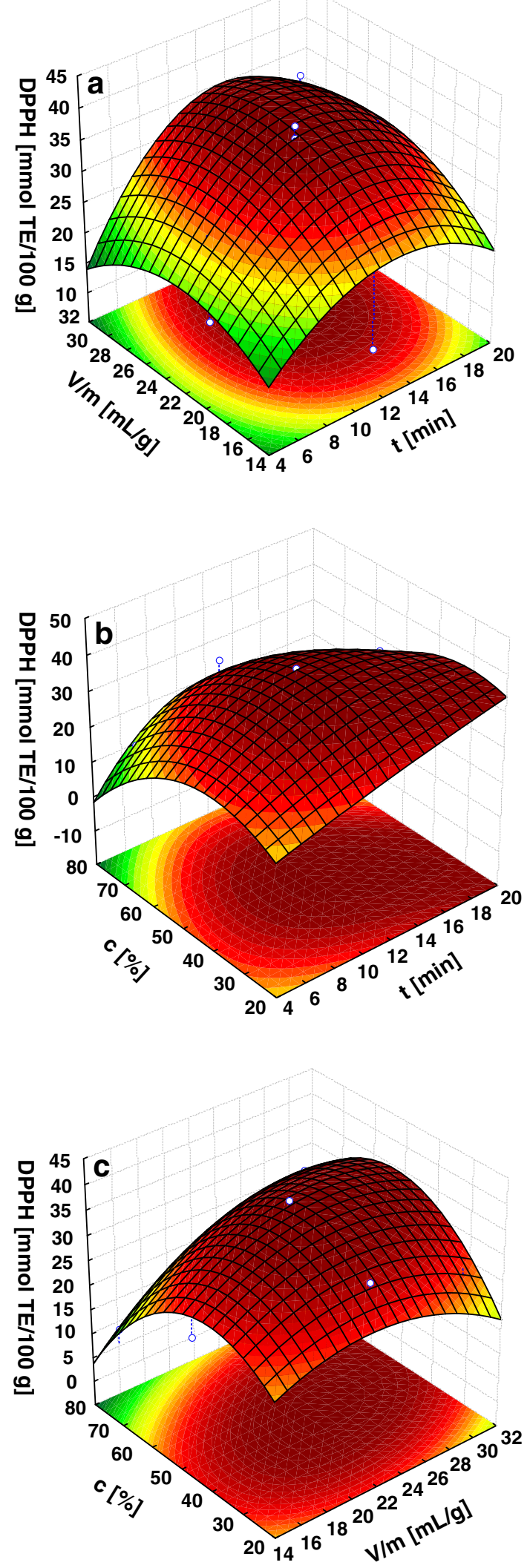

Winter rapeseed cultivar
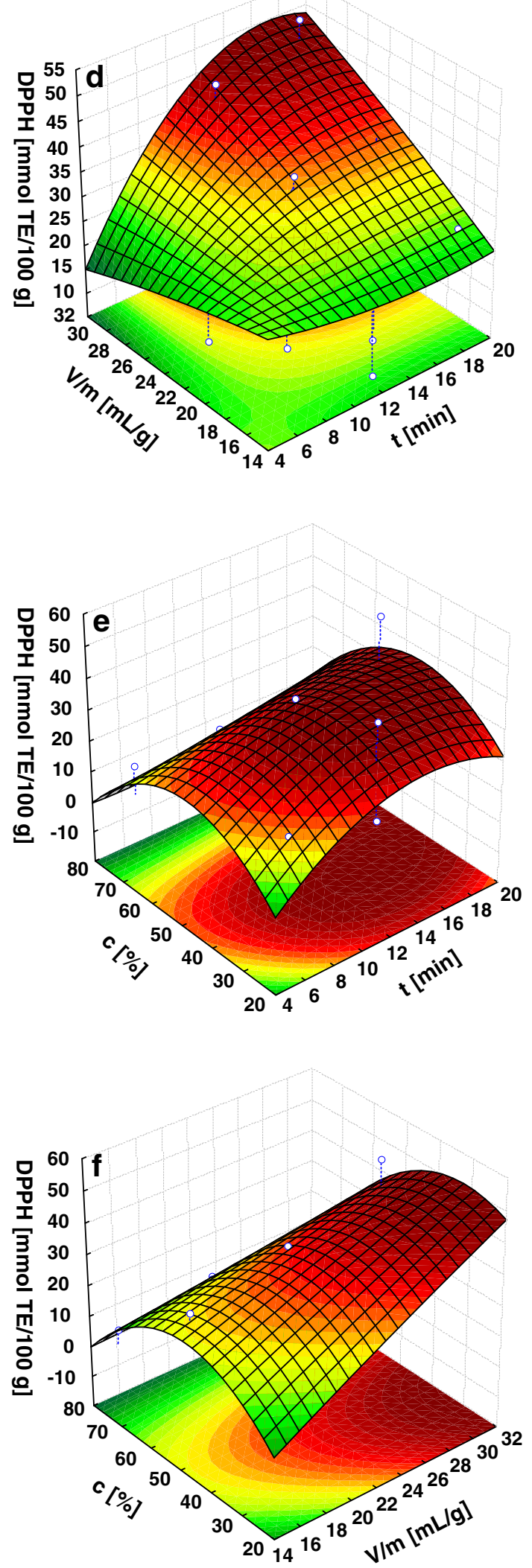
rapeseed varieties extracts. The calculated $R^{2}$ values indicate that obtained PCMs were adequate for the description of effects of the three independent variables $(t, V / m$, and $c)$ on antioxidant capacity of spring and winter rapeseed varieties determined by two proposed assays. The $R^{2}$ and the adjusted $R^{2}$ values for the ABTS of winter rapeseed cultivar extracts and DPPH of spring rapeseed cultivar extracts were higher than 0.90 ; hence, there is a close agreement between the experimental results and theoretical values predicted by the proposed models.

The model adequacy was tested using the lack-of-fit $F$ test, which was not significant for $p>0.05$. The ANOVA results of ABTS for winter rapeseed extracts and DPPH for spring rapeseed extracts revealed insignificant lack of fit $(F$ value $=$ 0.08 and $2.0, p>0.05$, respectively) (Table 3 ). Therefore, these models were adequate for prediction within the range of variables employed. However, significant lack of fit of two models (ABTS and DPPH of spring and winter rapeseed extracts, respectively) indicates that other factors are affecting the antioxidant capacity of the studied samples.

Furthermore, the linear and quadratic effects of the independent variables $(t, V$, and $c)$ and their interactions on the response variables (ABTS and DPPH) were analyzed by ANOVA. The model is highly significant when the computed $F$ value is greater than the tabulated $F$ value and a probability value is low $(p<0.01)$. Only solvent-to-material ratio (linear and quadratic terms) and interaction $t^{2} \times V / m$ were insignificant for ABTS of spring rapeseed variety. However, three parameters $\left(c^{2}, c\right.$, and $\left.t^{2}\right)$ revealed significant effects on DPPH of spring rapeseed cultivar. Moreover, all quadratic terms, one linear term of sonication treatment time, and two interaction parameters $\left(t^{2} \times V / m\right.$ and $\left.V / m \times c\right)$ of the model were statistically significant $(p<0.05)$ for ABTS of winter rapeseed extracts. On the contrary, all linear terms and one quadratic term of methanol concentration with interaction between $\mathrm{VI}$ $m \times c$ caused significant effects on DPPH values of winter rapeseed variety.

For comparison, only linear and quadratic terms (ethanol concentration, temperature, and time of the UAE) had statistically significant effects on DPPH of pomegranate peel. The ethanol concentration had the greatest impact on DPPH values of pomegranate peel extracts (Tabaraki et al. 2012).

\section{Analysis of Response Surfaces}

It can be noted that the shapes of response surfaces for ABTS and DPPH of spring and winter cultivars were different from each other (Figs. 1 and 2).

The elliptical shapes of the contour plots indicate the significant interactions between the independent variables such as sonication time, volume of methanol-to-rapeseed weight ratio, and methanol concentration (Figs. 1 and 2). The parabolic shapes of ABTS surfaces were caused by the positive values of the quadratic terms of all independent variables (except $(V / m)^{2}$ for spring rapeseed extracts), whereas the same quadratic parameters $\left(c^{2}\right.$ and $\left.t^{2}\right)$ and only concentration of methanol $\left(c^{2}\right)$ affected positively on DPPH values of spring and winter rapeseed variety, respectively (Figs. 1 and 2). The effects of methanol concentration and one of the extraction variables $(t$ or $V / m)$ demonstrated that the response surfaces of antioxidant capacity of the discussed extracts determined by the proposed ABTS and DPPH methods (except ABTS results for winter rapeseed variety) were similar to each other (Figs. 1 and 2). In these cases, the response surfaces and contour plots depicted a maximum at the highest $t(18 \mathrm{~min})$ or $\mathrm{V} / \mathrm{m}$ $(30 \mathrm{~mL} / \mathrm{g})$ and an intermediate $c=50 \%$.
Fig. 3 Dendrogram of hierarchical cluster analysis for the studied rapeseed extracts

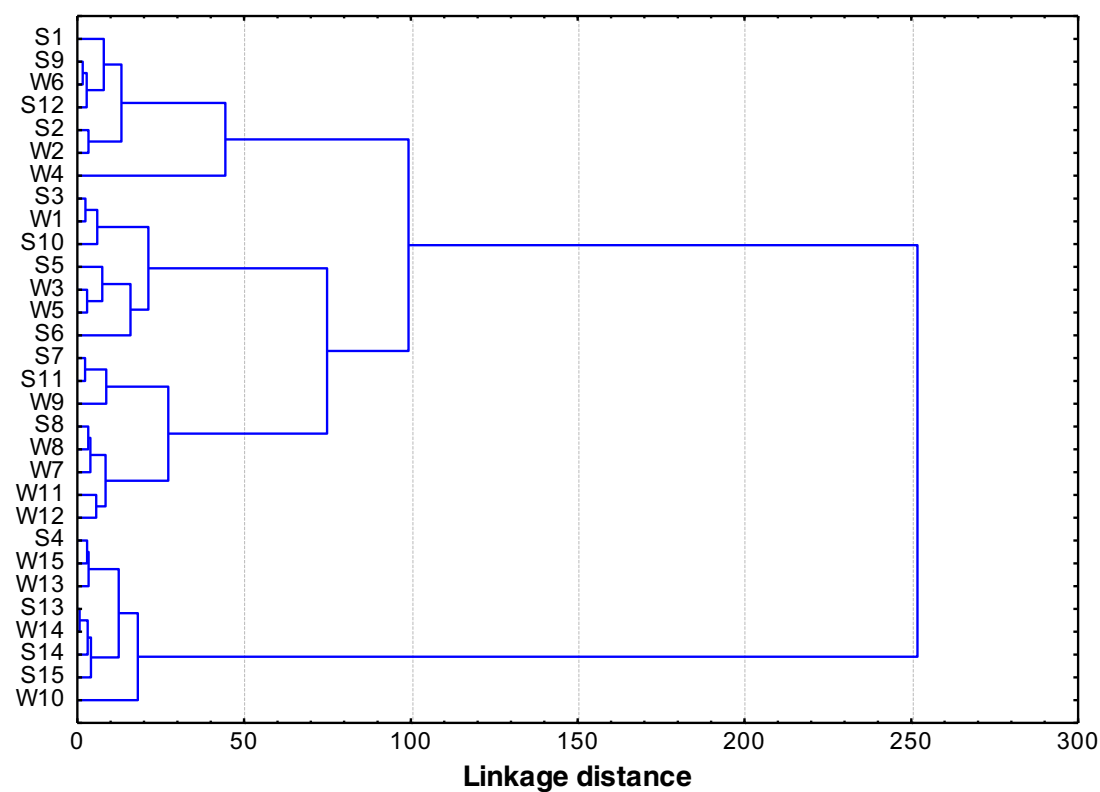


It is evident that ABTS values of winter rapeseed variety increase rapidly with the increasing concentration of solvent or $V / m$ ratio at the beginning but decreased slightly in later stages (Fig. 1e, f). Moreover, the significant positive linear effect of $t$ and $V / m$ on the DPPH of winter rapeseed variety resulted in the enhancement of antioxidant capacity along with the increase of time of ultrasound treatment and solvent-tomaterial ratio (Fig. 2d). In Fig. 2a, RSM reveals the maximum of DPPH at an intermediate sonication time and volume of methanol-to-spring rapeseed weight ratio.

The proposed mathematical models allow calculation of the optimum operating parameters of the UAE of total antioxidants from spring and winter rapeseed cultivars. The optimum conditions for extraction of antioxidants from the spring rapeseed variety were as follows: $t=13.8 \mathrm{~min}, V / \mathrm{m}=26.2 \mathrm{~mL} /$ $\mathrm{g}$, and $c=50.3 \%$, under which ABTS $=62.7 \mathrm{mmol} \mathrm{TE} / 100 \mathrm{~g}$ and $\mathrm{DPPH}=38.3 \mathrm{mmol} \mathrm{TE} / 100 \mathrm{~g}$ were predicted. Besides, the models predicted the ABTS $(62.0 \mathrm{mmol} \mathrm{TE} / 100 \mathrm{~g})$ and DPPH $(48.6 \mathrm{mmol} \mathrm{TE} / 100 \mathrm{~g})$ values of the winter rapeseed cultivar at the optimum conditions of $t=13.3 \mathrm{~min}, V / m=29.5 \mathrm{~mL} / \mathrm{g}$, and $c=38.3 \%$.

\section{Hierarchical Cluster Analysis}

Hierarchical cluster analysis (HCA) was applied to group the studied extracts of two rapeseed cultivars based on similarities in their antioxidant capacities determined by the proposed ABTS and modified DPPH methods. The obtained results are presented as a dendrogram in Fig. 3.

It can be noted that the 30 rapeseed extracts obtained under different conditions of the UAE were classified into three main clusters. Six samples (S1, S2, S9, S12, W2, and W6) were arranged in one group characterized by similar values of ABTS (42.8-51.3 mmol TE/100 g) and DPPH (20.7$29.0 \mathrm{mmol} \mathrm{TE} / 100 \mathrm{~g}$ ). The dendrogram depicted a clear separation of winter seed W4 with the highest DPPH (51.6 mmol TE/100 g) and low ABTS (34.5 mmol TE/ $100 \mathrm{~g}$ ) values, respectively (Tables 1 and 2). The second group including 15 extracts was quite separated, because they had the moderate antioxidant capacities. Although, samples S7, S8, S11, W7, W8, W9, W11, and W12 with low DPPH values created the inter-cluster (Fig. 3, Table 2). However, extracts S13-S15, W13-W15 obtained under the same conditions $(t=$ $12 \mathrm{~min}, V / m=22.5 \mathrm{~mL} / \mathrm{g}, c=50 \%$ ), as well as $\mathrm{S} 4,50 \%$ methanolic extract of spring variety $(t=18 \mathrm{~min}, \mathrm{~V} / \mathrm{m}=$ $30 \mathrm{~mL} / \mathrm{g}$ ) and $\mathrm{W} 10,25 \%$ methanolic extract of winter variety ( $t=12 \mathrm{~min}, V / \mathrm{m}=30 \mathrm{~mL} / \mathrm{g}$ ) formed an evidently distinct cluster. This group of rapeseed samples generaly had high antioxidant capacity determined by the proposed analytical methods. The dendrogram revealed that the grouping of the 30 rapeseed extracts is dependent of extraction conditions (ultrasonication time, volume of methanol-to-rapeseed weight ratio, and solvent concentration), which would affect the total level of antioxidants.

\section{Conclusion}

The RSM appeared to be useful for studying the influence of extraction conditions, such as ultrasonication time, volume of methanol-to-rapeseed weight ratio, and solvent concentration on antioxidant capacity of the resulting rapeseed extracts determined by the proposed ABTS and the modified DPPH methods. The partial cubic model can be applied to optimize the parameters of the UAE to obtain rapeseed extracts with potent antioxidant capacity. Solvent concentration has a greater effect than the ultrasonication time and volume of methanol-to-rapeseed weight ratio on all DPPH results and ABTS values of spring rapeseed cultivar. However, time of ultrasound treatment of winter rapeseed cultivar was more effective independent variable on ABTS results of the obtained extracts. It is noteworthy that winter rapeseed variety is somewhat richer source of antioxidants than spring rapeseed cultivar. Moreover, the results of HCA indicated that conditions of the UAE had significant influence on antioxidant capacity of two rapeseed cultivars. The UAE appears to have great potential as technique for the extraction of antioxidants from rapeseed varieties, whereas the proposed ABTS and the modified DPPH methods are relatively simple, precise, and convenient for the determination of antioxidant capacity of rapeseed extracts, and along with RSM can be employed by the oil processing industry for producing rapeseed oil with high content of bioactive compounds.

Acknowledgments The authors wish to thank Polish Ministry of Science and Higher Education for the financial support: Grant No. N N312 465740 .

Conflict of Interest Aleksandra Szydłowska-Czerniak declares that she has no conflict of interest.

Agnieszka Tułodziecka declares that he has no conflict of interest.

This article does not contain any studies with human or animal subjects.

Open Access This article is distributed under the terms of the Creative Commons Attribution License which permits any use, distribution, and reproduction in any medium, provided the original author(s) and the source are credited.

\section{References}

Ahmad-Qasem MH, Cánovas J, Barrajón-Catalán E, Micol V, Cárcel JA, García-Pérez JV (2013) Kinetic and compositional study of phenolic extraction from olive leaves (var. Serrana) by using power ultrasound. Innov Food Sci Emerg Technol 17:120-129 
Amarowicz R, Naczk M, Shahidi F (2000) Antioxidant activity of crude tannins of canola and rapeseed hulls. J Am Oil Chem Soc 77:957961

Amarowicz R, Raab B, Shahidi F (2003) Antioxidant activity of phenolic fractions of rapeseed. J Food Lipids 10:51-62

Chemat F, E-Huma Z, Khan MK (2011) Applications of ultrasound in food technology: processing, preservation and extraction. Ultrason Sonochem 18:813-835

Dwiecki K, Siger A, Czubiński J, Nogala-Kałucka M, Lampart-Szczapa $\mathrm{E}$ (2012) The interactions between rapeseed lipoxygenase and native polyphenolic compounds in a model system. J Am Oil Chem Soc 89:379-387

Farag MA, Sharaf Eldin MG, Kassem H, Abou el Fetouh M (2013) Metabolome classification of Brassica napus L. organs via UPLC-QTOF-PDA-MS and their anti-oxidant potential. Phytochem Anal 24:277-287

Friedt W, Snowdon R, Ordon F, Ahlemeyer J (2007) Plant breeding: assessment of genetic diversity in crop plants and its exploitation in breeding. Progress Bot 68:151-178

Khattab R, Goldberg E, Lin L, Thiyam U (2010) Quantitative analysis and free radical-scavenging activity of chlorophyll, phytic acid, and condensed tannins in canola. Food Chem 122:1266-1272

Maltas E, Yildiz S (2011) Distribution of secondary metabolites in Brassica napus genotypes. J Food Biochem 35:1071-1082

Matthäus B (2002) Antioxidant activity of extracts obtained from residue of different oilseeds. J Agric Food Chem 50:3444-3452

Morelli LLL, Prado MA (2012) Extraction optimization for antioxidant phenolic compounds in red grape jam using ultrasound with a response surface methodology. Ultrason Sonochem 19: $1144-1149$

Muñiz-Márquez DB, Martínez-Ávila GC, Wong-Paz JE, Belmares-Cerda R, Rodríguez-Herrera R, Aguilar CN (2013) Ultrasound-assisted extraction of phenolic compounds from Laurus nobilis L. and their antioxidant activity. Ultrason Sonochem 20:1149-1154

Prior RL, Wu X, Schaich K (2005) Standardized methods for the determination of antioxidant capacity and phenolics in foods and dietary supplements. J Agric Food Chem 53:4290-4302
Re R, Pellegrini N, Proteggente A, Pannala A, Yang M, Rice-Evans C (1999) Antioxidant activity applying an improved ABTS radical cation decolorization assay. Free Radic Bio Med 26:1231-1237

Shahidi F, Naczk M (1992) An overview of the phenolics of canola and rapeseed: chemical, sensory and nutritional significance. J Am Oil Chem Soc 69:917-924

Szydłowska-Czerniak A (2013) Rapeseed and its products - sources of bioactive compounds: a review of their characteristics and analysis. Crit Rev Food Sci Nutr 53:307-330

Szydłowska-Czerniak A, Tułodziecka A (2013) Comparison of a silver nanoparticle-based method and the modified spectrophotometric methods for assessing antioxidant capacity of rapeseed varieties. Food Chem 141:1865-1871

Szydłowska-Czerniak A, Trokowski K, Karlovits G, Szłyk E (2010) Determination of antioxidant capacity and phenolic acids in rapeseed varieties. J Agric Food Chem 58:7502-7509

Szydłowska-Czerniak A, Bartkowiak-Broda I, Karlović I, Karlovits G, Szłyk E (2011) Antioxidant capacity, total phenolics, glucosinolates and colour parameters of rapeseed cultivars. Food Chem 127:556563

Tabaraki R, Heidarizadi E, Benvidi A (2012) Optimization of ultrasonicassisted extraction of pomegranate (Punica granatum L.) peel antioxidants by response surface methodology. Sep Purif Technol 98: $16-23$

Wang J, Sun B, Cao Y, Tian Y, Li X (2008) Optimisation of ultrasoundassisted extraction of phenolic compounds from wheat bran. Food Chem 106:804-810

Wang X-S, Wu Y-F, Dai S-L, Chen R, Shao Y (2012) Ultrasound-assisted extraction of geniposide from Gardenia jasminoides. Ultrason Sonochem 19:1155-1159

Yang M, Zheng C, Zhou Q, Huang F, Liu C, Wang H (2013) Minor components and oxidative stability of cold-pressed oil from rapeseed cultivars in China. J Food Compos Anal 29:1-9

Yoshie-Stark Y, Wada Y, Schott M, Wäsche A (2006) Functional and bioactive properties of rapeseed protein concentrates and sensory analysis of food application with rapeseed protein concentrates. LWT Food Sci Technol 39:503-512 